\title{
Novos registros de fungos anamorfos (hifomicetos) para o Neotrópico e América do Sul ${ }^{1}$
}

\author{
CARLA CORRÊA DE CASTRO², ANTONIO HERNÁNDEZ GUTIÉRREZ e \\ HELEN MARIA PONTES SOTÃO ${ }^{2,4}$
}

(recebido: 23 de março de 2011; aceito: 08 de setembro de 2011)

\begin{abstract}
New records of anamorphic fungi (hyphomycetes) for the Neotropics and South America). Floristic structure and climatic conditions of tropical rainforests characterize ecosystems where very diverse fungal populations proliferate. Amongst those, the Amazonia is recognized as the biggest existing tropical forest in the world. However, taxonomic studies on hyphomycetes fungi in this region are scarce. The objective of this work was to investigate the occurrence of conidial fungi (hyphomycetes) associated to the decomposition of dead parts of Euterpe oleracea Mart.(açaizeiro), Arecaceae. From August 2008 to April 2009 decaying parts of this palm tree were collected in the Combu Island, an Environmental Protection Area, at the city of Belém, Pará. As partial result of this study, two new records of Hyphomycetes for the Neotropics (Digitodesmium recurvum W. H. Ho, K. D. Hyde \& Hodgkiss and Pithomyces karoo Marasas \& I. H. Schum.) and other new 10 fungal species records for South America were found. Taxonomic descriptions, commentaries, geographic distribution and illustrations for each new record are given.
\end{abstract}

Key words - açaí, Amazônia, diversity, mitosporic fungi, palm

RESUMO - (Novos registros de fungos anamorfos (hifomicetos) para o Neotrópico e América do Sul). Por suas condições estruturais e climáticas as florestas tropicais são ecossistemas onde prolifera uma grande diversidade fúngica. A Amazônia é reconhecida como a maior floresta tropical existente. No entanto, estudos taxonômicos sobre fungos hifomicetos nesta região são escassos. Este trabalho teve como objetivo investigar a ocorrência de hifomicetos associados a partes em decomposição da Arecaceae Euterpe oleracea Mart. (açaizeiro). Entre agosto de 2008 e abril de 2009 foram coletadas partes em decomposição de açaizeiro na Área de Proteção Ambiental Illha do Combu, Município de Belém, Pará. Como parte dos resultados deste estudo foram encontrados dois novos registros para o Neotrópico (Digitodesmium recurvum W. H. Ho, K. D. Hyde \& Hodgkiss e Pithomyces karoo Marasas \& I. H. Schum.) e 10 para a América do Sul. O presente trabalho contém descrições taxonômicas, comentários, distribuição geográfica e ilustrações para cada um dos novos registros.

Palavras-chave - açaí, Amazônia, diversidade, fungos mitospóricos, palmeira

\section{Introdução}

A micota é uma comunidade importante da biodiversidade, essencial para a sobrevivência de outros organismos e crucial nos processos ecológicos vitais para a manutenção dos ecossistemas (Subramanian 1982, Hawksworth 2002). Os hifomicetos participam do processo de decomposição de diversos substratos nos ecossistemas, em particular os de origem vegetal, sendo o grupo mais numeroso dentre os fungos anamórficos ocorrendo em abundância no folhedo (Grandi \& Gusmão 2002).

1. Parte da dissertação de mestrado do primeiro autor, Programa de Pós-Graduação em Botânica Tropical, Universidade Federal Rural da Amazônia/Museu Paraense Emílio Goeldi, Belém, PA, Brasil.

2. Museu Paraense Emílio Goeldi - MPEG, Coordenação de Botânica, Laboratório de Micologia, Av. Perimetral 1901, Caixa Postal 399, 66077-830 Belém, PA, Brasil.

3. Universidade Federal do Pará - UFPA, Instituto de Ciências Biológicas, Rua Augusto Corrêa 01, Caixa Postal 479, 66075-110 Belém, PA, Brasil.

4. Autor para correspondência: helen@museu-goeldi.br
Por suas condições estruturais e climáticas, as florestas tropicais são ecossistemas onde prolifera uma grande diversidade fúngica. Entre estas, a Amazônia é reconhecida como a maior floresta tropical existente (Cáuper et al. 2006). No entanto, estudos taxonômicos sobre fungos hifomicetos nesta região são escassos (Farr 1980, 1986, Cruz et al. 2008). Para o Estado do Pará, Hernández-Gutiérrez et al. (2009) registraram 66 táxons de hifomicetos encontrados sobre partes em decomposição de palmeiras coletadas na Floresta Nacional de Caxiuanã (PA), com 18 espécies ocorrendo em Euterpe oleracea Mart. (açaizeiro). Monteiro et al. (2010), também em Caxiuanã, em um sítio de estudo do Programa de Pesquisa em Biodiversidade da Amazônia (PPBio) constataram cinco novos registros para o Neotrópico. Especificamente para a Ilha do Combu associado à palmeira E. oleracea encontramse os trabalhos de Rodrigues (1994), que identificou 57 espécies de fungos endofíticos, incluindo alguns hifomicetos, e Negrão et al. (2009) que encontraram seis gêneros de hifomicetos sobre estipes de açaizeiros. 
A carência de levantamentos sobre a diversidade dos fungos na Amazônia, principalmente dos hifomicetos, somada à rápida degradação da sua vegetação, evidenciam a necessidade urgente de estudos intensivos, principalmente em áreas que sofrem pressão antrópica, por se localizar no entorno das grandes cidades.

Este trabalho teve como objetivos descrever e ilustrar espécies de fungos hifomicetos decompositores, coletados na Área de Proteção Ambiental (APA) Ilha do Combu, que constituem novos registros para o Neotrópico e América do Sul, apresentando comentários e a distribuição geográfica das espécies.

\section{Material e métodos}

No período de agosto de 2008 a abril de 2009 foram coletadas partes em decomposição de Euterpe oleracea em oito transectos de $10 \times 100 \mathrm{~m}$, na APA da Ilha do Combu, no Município de Belém, Pará, cujas coordenadas de referência são: $1^{\circ} 29^{\prime} 20^{\prime}$ 'S e 48 $25^{\prime} 54^{\prime}$ ' W. Cinco amostras compostas por bainhas, pecíolos, raques, folíolos, espatas, cachos, estipes e raízes, originadas de cada transecto, foram mantidas em câmara úmida durante sete dias (Choi et al. 1999). Após esse período, foram colocadas para secar em estufa por 24 horas, a uma temperatura de aproximadamente $60^{\circ} \mathrm{C}$ e, em seguida, mantidas sob refrigeração $\left(-20^{\circ} \mathrm{C}\right)$, para evitar a invasão e deterioração dos fungos por ácaros.

Sob o microscópio estereoscópico, os fungos foram extraídos com auxílio de agulha microbiológica de ponta afilada e montados em lâminas semipermanentes no meio de montagem lactoglicerol, com ou sem o corante azul de algodão, dependendo da existência de estruturas hialinas ou muito claras ou de septação obscura. Para a identificação e descrição das espécies foram realizadas análises morfológicas e medições micrométricas das estruturas somáticas e reprodutivas dos espécimes e comparação com a literatura especializada, tais como: Ellis (1976) e Matsushima (1975, 1981). As amostras foram depositadas no Herbário do Museu Paraense Emílio Goeldi (MG).

\section{Resultados e discussão}

Neste estudo foram obtidos dois novos registros de hifomicetos para o Neotrópico (Digitodesmium recurvum W. H. Ho, K. D. Hyde \& Hodgkiss e Pithomyces karoo Marasas \& I. H. Schum.) e 10 para a América do Sul.

Acrodictys elaeidis J. M. Yen \& Sulmont, Cah. Maboke 8(1): 35. 1970.

Figura 1

Colônias em substrato natural efusas. Conidióforos macronemáticos, mononemáticos, retos ou flexuosos, simples, septados, lisos, castanho-claros, 9-31 × $6 \mu \mathrm{m}$. Células conidiogênicas monoblásticas, terminais, integradas, anelídicas. Conídios solitários, 6-7 septos transversais, frequentemente com um septo longitudinal ou uma protuberância lateral, levemente constritos nos septos, secos, lisos, castanhos ou castanho-escuros, elipsoides, células apicais e basais mais claras, 30$37 \times 16-20 \mu \mathrm{m}$, base truncada com 6-7 $\mu \mathrm{m}$ de largura.

Material examinado: BRASIL, PARÁ: Belém, Ilha do Combu, sobre bainha de E. oleracea, 20-VIII-2008, C.C. Castro 36 (MG199637), pecíolo, 15-XI-2008, C.C. Castro 37 (MG199638).

Distribuição geográfica: Cuba (Mercado-Sierra 1984), Gabão (Ellis 1976), México (Heredia et al. 1997) e Tanzânia (Pirozynski 1972).

Comentários: As protuberâncias laterais desenvolvidas nos conídios jovens são as características distintivas de A. elaeidis. Pirozynski (1972) considerou tais estruturas como corpos semelhantes a picnídios, e com base nisso propôs a transferência de $A$. elaeidis para o gênero Septosporium Corda. No entanto, as espécies de Septosporium apresentam setas numerosas e conídios muriformes, enquanto que $A$. elaeidis não possui setas, seus conídios apresentam 6-7 septos transversais e frequentemente um septo longitudinal e base truncada, o que justifica a permanência desta espécie no gênero Acrodictys. Os espécimes examinados apresentaram conídios menores que os descritos em literatura ocorrendo sobre palmeiras: $30-50 \times 16-22 \mu \mathrm{m}$ (Ellis 1976); $37-54 \times 15,5-28 \mu \mathrm{m}$ (Mercado-Sierra 1984); 35-41 $\times$ 16-19 $\mu \mathrm{m}$ (Heredia et al. 1997).

Arachnophora hughesii R. F. Castañeda \& Guarro, Can. J. Bot. 76(9): 1584. 1999.

Figuras 2-4

Colônias em substrato natural efusas. Conidióforos macronemáticos, mononemáticos, retos ou flexuosos, simples, 5-7-septados, lisos, castanhos na base, castanhoclaros no ápice, 91-128 × $6 \mu \mathrm{m}$. Células conidiogênicas monoblásticas, terminais, integradas, anelídicas. Conídios holoblásticos, solitários, secos, lisos, estaurospóricos, 21-28 $\times 18-23 \mu \mathrm{m}$, compostos por três partes: a) célula basal obcônica, inflada, castanho-clara, 6-10 × 6-8 $\mu \mathrm{m}$, 2-3 $\mu \mathrm{m}$ de largura na base; b) 1-2 células centrais subdoliformes, castanhas, $7-13 \times 10-14 \mu \mathrm{m}$ e c) $2-6$ ramos que surgem das células centrais, 0 -1-septados, constritos no septo, 6-14 $\mu \mathrm{m}$ de comprimento com a célula basal inflada castanho-clara e a célula apical cônica, sub-hialina; liberação rexolítica dos conídios. Sinanamorfo: a célula apical de cada ramo conidial 


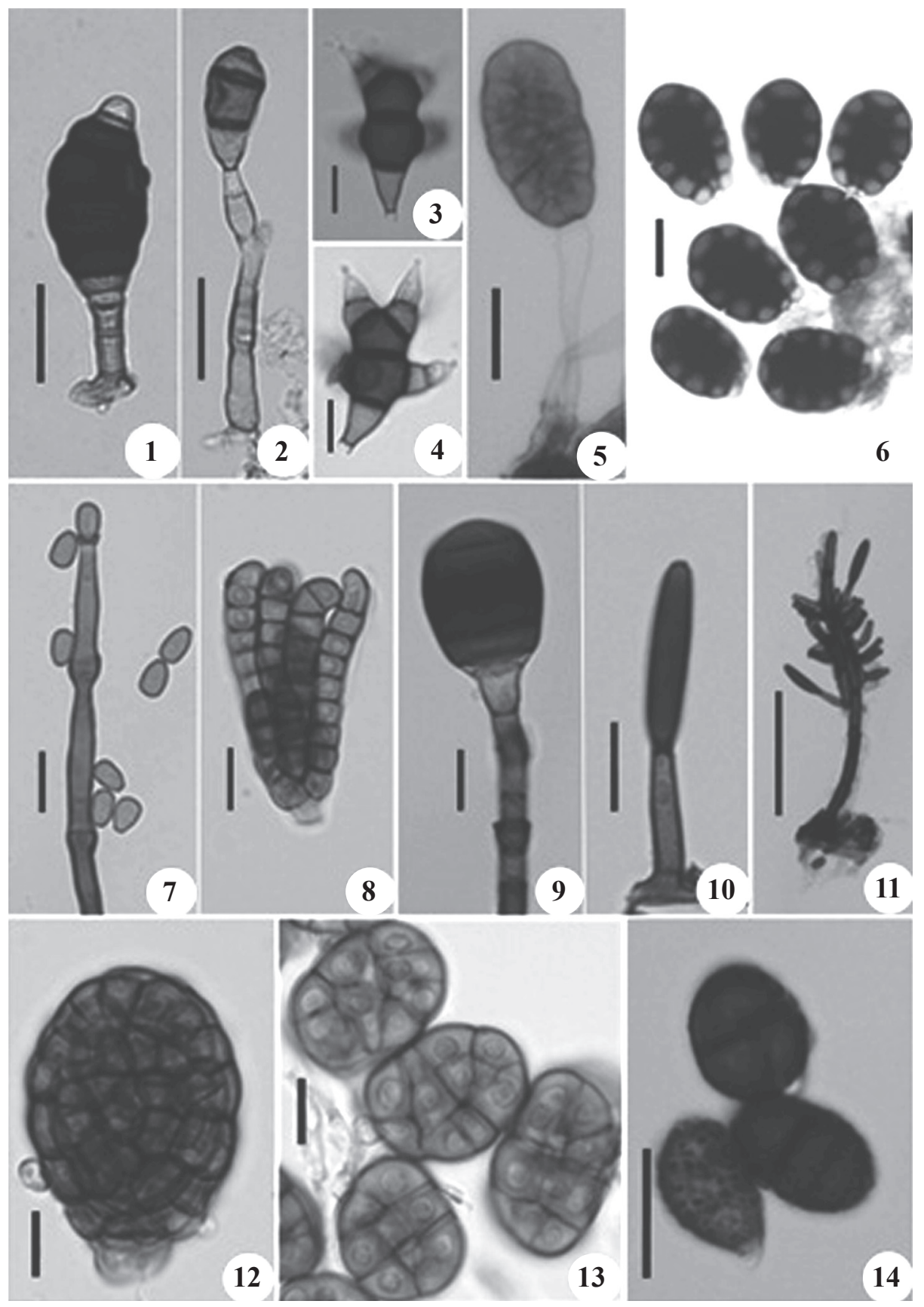

Figuras 1-14. Conídios e conidióforos de hifomicetos coletados na Ilha do Combu, sobre palmeiras. 1. Acrodictys elaeidis conidióforo e conídio. 2-4. Arachnophora hughesii. 2. Conidióforo. 3-4. Conídios. 5. Berkleasmium inflatum - conídio. 6. Canalisporium kenyense - conídios. 7. Catenularia cubensis - detalhe do ápice do conidióforo e conídios. 8. Digitodesmium recurvum - conídio. 9. Endophragmiella mexicana - detalhe do ápice do conidióforo e conídio. 10-11. Hemicorynespora aseptata. 10. Conidióforo e conídio. 11. H. aseptata sobre Corynesporopsis isabelicae. 12. Monodictys paradoxa-conídio. 13. Pithomyces cinnamomeus - conídios. 14. Pithomyces karoo - conídios. Barra $=10 \mu \mathrm{m}(2,3,4,7,8,9,10,12,13) ; 20 \mu \mathrm{m}(1,5,6,14) ; 50 \mu \mathrm{m}(11)$.

Figures 1-14. Conidia and conidiophores of hyphomycetes collected in Combu Island on palm trees. 1. Acrodictys elaeidis conidiophore and conidium. 2-4. Arachnophora hughesii. 2. Conidiophore. 3-4. Conidia. 5. Berkleasmium inflatum conidium. 6. Canalisporium Kenyense - conidia. 7. Catenularia cubensis - detail of conidiophore in the apex and conidia. 8. Digitodesmium recurvum - conidium. 9. Endophragmiella mexicana - detail of conidiophore in the apex and conidium. 10-11. Hemicorynespora aseptata. 10. Conidiphore and conidium. 11. H. aseptata on Corynesporopsis isabelicae. 12. Monodictys paradoxa - conidium. 13. Pithomyces cinnamomeus - conidia. 14. Pithomyces karoo - conidia. Bar $=10 \mu \mathrm{m}(2,3,4,7,8,9$, $10,12,13) ; 20 \mu \mathrm{m}(1,5,6,14) ; 50 \mu \mathrm{m}(11)$. 
produz conídios blásticos, fusiformes, 0-septados, hialinos, 3-4 × 1-1,5 $\mu \mathrm{m}$.

Material examinado: BRASIL, PARÁ: Belém, Ilha do Combu, sobre cacho de E. oleracea, 20-VIII-2008, C.C. Castro 5-1. (MG195841).

Distribuição geográfica: Cuba (Castañeda-Ruiz \& Guarro 1998).

Comentários: o gênero Arachnophora Hennebert possui seis espécies descritas; destas, apenas $A$. hughesii e A. polyradiata (Mercado \& R. F. Castañeda) R. F. Castañeda \& W. Gams apresentam sinanamorfo produzido pela célula apical dos ramos conidiais. Porém, A. polyradiata possui os conídios maiores $(28-40 \times$ 25-38 $\mu \mathrm{m})$ e os ramos conidiais com 2-3 septos, enquanto em A. hughesii os conídios medem 21-28 × 18-23 $\mu \mathrm{m} \mathrm{e}$ ramos conidiais $0-1$ septados.

Berkleasmium inflatum Hol.-Jech., Česká Mykol. 41(1): 29. 1987.

Figura 5

Esporodóquios granulares, castanhos, brilhantes. Conidióforos macronemáticos, monemáticos, retos, raramente flexuosos, simples, raramente septados, lisos, hialinos, 19-50 × 2,5-6 $\mu \mathrm{m}$, ápice inflado 6-9 $\mu \mathrm{m}$ de largura. Células conidiogênicas monoblásticas, terminais, integradas, determinadas, lisas, hialinas, infladas, clavadas ou cilíndricas. Conídios acrógenos, solitários, levemente constritos nos septos, muriformes, secos, lisos, castanho-dourados, elipsoides ou obovoides, $36-49 \times 17-22 \mu \mathrm{m}$.

Material examinado: BRASIL, PARÁ: Belém, Ilha do Combu, sobre bainha de E. oleracea, 20-VIII-2008, C.C. Castro 12 (MG195848), espata, 27-VIII-2008, C.C. Castro 17 (MG 195853), cacho, 15-IX-2009, C.C. Castro 38 (MG199639).

Distribuição geográfica: China (Zhao \& Zhang 2004) e Cuba (Holubová-Jechová \& Mercado-Sierra 1989).

Comentários: Berkleasmium inflatum se assemelha a B. typhae Somrithipol \& E. B. G. Jones, pois ambos possuem os conidióforos inflados. Contudo, em $B$. typhae os conídios $(23-28,5 \times 15-19,5 \mu \mathrm{m})$ e conidióforos $(21,5 \mu \mathrm{m})$ são menores (Somrithipol \& Jones 2003). Os espécimes examinados diferem da descrição original, na qual os conidióforos apresentaram 1-3 células infladas (Holubová-Jechová $\&$ Mercado-Sierra 1989). No entanto, concordam com os espécimes de Zhao \& Zhang (2004), que apresentaram conidióforos com apenas uma célula inflada.
Canalisporium kenyense Goh, W. H. Ho \& K. D. Hyde, in Goh, Ho, Hyde, Whitton \& Umali, Can. J. Bot. 76(1): 148. 1998.

Figura 6

Esporodóquios granulares, negros, brilhantes. Conidióforos e células conidiogênicas não observados. Conídios acrógenos, solitários, coplanados, muriformes, 3-5 septos transversais e 2 septos longitudinais, levemente constritos nos septos, secos, lisos, paredes espessas, castanho-avermelhados ou castanho-escuros, elipsoides ou piriformes, 32-47 $\times$ $19-28 \times 14-20 \mu \mathrm{m}$. Fileiras apicais mais escuras que as basais, células das extremidades mais claras que as do centro, ápice composto por apenas uma célula, base composta por três células pequenas com paredes finas, organizadas em fileira única. Secessão conidial rexolítica.

Material examinado: BRASIL, PARÁ: Belém, Ilha do Combu, sobre raque de E. oleracea, 03-IV-2009, C.C. Castro 64 (MG199665).

Distribuição geográfica: Quênia (Goh et al. 1998) e Panamá (Ferrer \& Shearer 2005).

Comentários: das dez espécies do gênero Canalisporium Nawawi \& Kuthubutheen, C. kenyense é a única que apresenta conídios com três pequenas células basais e ápice com uma célula, as demais espécies possuem apenas uma célula basal e duas ou mais células apicais. $\mathrm{Na}$ descrição original de Goh et al. (1998) procedente do Quênia, os conídios são maiores $(34-56 \times 24-34 \times 14-18 \mu \mathrm{m})$ que os espécimes examinados $(32-47 \times 19-28 \times 14-20 \mu \mathrm{m})$ que apresentaram dimensões mais próximas as dos espécimes do Panamá $(30-46 \times 22-30 \mu \mathrm{m})($ Ferrer \& Shearer 2005).

Catenularia cubensis Hol.-Jech., Mycotaxon 15: 278. 1982.

Figura 7

Colônias em substrato natural efusas. Conidióforos macronemáticos, mononemáticos, retos ou flexuosos, simples, septados, lisos, castanho-claros, 85-143 $\times$ 3-4 $\mu \mathrm{m}$. Células conidiogênicas fialídicas, terminais, integradas, percurrentes, lisas, com um colarete apical. Conídios endógenos, geralmente em cadeias, 0 -septados, secos, lisos, castanho-claros, obcônicos, 6-7 × $4 \mu \mathrm{m}$, base truncada com 2-3 $\mu \mathrm{m}$ de largura.

Material examinado: BRASIL, PARÁ: Belém, Ilha do Combu, sobre bainha de E. oleracea, 20-VIII-2008, C.C. Castro 1-2 (MG195837), raque, 03-IV-2009, C.C. Castro 41 (MG199642). 
Distribuição geográfica: Cuba (Holubová-Jechová 1982).

Comentários: Catenularia cubensis é o estado anamorfo de Chaetosphaeria cubensis Hol.-Jech. e diferencia-se das outras espécies do gênero por possuir conídios pequenos de 5,5-9 × 3,5-5,5 $\mu \mathrm{m}$ na descrição

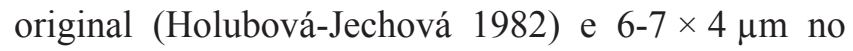
material estudado. As espécies mais próximas de $C$. cubensis são: C. cuneiformis (Richon) E. W. Mason, que possui conídios maiores $(10-14,5 \times 6,6-10,6 \mu \mathrm{m})$ (Holubová-Jechová 1982) e C. kalakadensis Subram. $\&$ Bhat cujos conídios possuem o ápice hexa-angular (Subramanian \& Bhat 1987).

Digitodesmium recurvum W. H. Ho, K. D. Hyde \& Hodgkiss, Mycologia 91(5): 900. 1999.

Figura 8

Esporodóquios pulvinados, castanhos. Células conidiogênicas e conidióforos não observados. Conídios holoblásticos, solitários, levemente constritos nos septos, secos, lisos, castanho-claros, queiroides, com 4-7 colunas inseridas na célula basal em diferentes planos; célula basal lisa, castanho-clara, truncada, paredes finas; colunas evidentes, cilíndricas, 28-43 × 5-7 $\mu \mathrm{m}$, com 8-13 células, célula apical recurvada, liberação dos conídios esquizolítica.

Material examinado: BRASIL, PARÁ: Belém, Ilha do Combu, sobre pecíolo de E. oleracea, 16-IX-2008, C.C. Castro 26 (MG199627).

Distribuição geográfica: China (Ho et al. 1999).

Comentários: Digitodesmium elegans P. M. Kirk é a espécie mais próxima de $D$. recurvum, porém $D$. elegans apresenta as colunas conidiais em menor número e com a célula apical não recurvada, além de apresentar, ocasionalmente, um capuz gelatinoso hialino no ápice das colunas. As características do material examinado estão de acordo com a descrição original (Ho et al. 1999).

Endophragmiella mexicana J. Mena, Heredia \& Mercado, in Mercado Sierra, Heredia \& Mena Portales, Mycotaxon 55: 496. 1995.

Figura 9

Colônias em substrato natural efusas. Conidióforos macronemático, mononemático, retos, simples, septados, lisos, castanhos a castanho-claros, ápice mais claro, 62-165 × 5-6 $\mu \mathrm{m}$. Células conidiogênicas monoblásticas, terminais, integradas, percurrentes, lisas, 11-14 × 3-5 $\mu \mathrm{m}$. Conídios solitários, acrógenos, com 4 septos transversais, secos, lisos, parede fina, castanho-escuros, com as células basal e apical subhialinas ou castanho-claras, elipsoides ou obovoides, 34-46 × 16-22 $\mu \mathrm{m}$.

Material examinado: BRASIL, PARÁ: Belém, Ilha do Combu, sobre bainha de E. oleracea, 16-IX-2008 C.C. Castro 29 (MG199630), cacho, 20-VIII-2008, C.C. Castro 6(MG195842), espata, 27-VIII-2008, C.C. Castro 17 (MG195853), pecíolo, 03-IV-2009, C.C. Castro 42 (MG199643), raque, C.C. Castro 61 (MG199662).

Distribuição geográfica: China (Ho et al. 2002) e México (Mercado-Sierra et al. 1995).

Comentários: Endophragmiella mexicana apresenta semelhanças com E. biseptata (Peck) S. Hughes (Hughes 1978) e E. fallacia P. M. Kirk (Kirk 1981), porém estas espécies apresentam conídios 2-septados com apenas a célula basal clara e as demais escuras, enquanto em E. mexicana os conídios são 4-septados com células basais e apicais claras. E. naromoruensis P. M. Kirk é a espécie mais próxima de $E$. mexicana, no entanto possui conídios elipsoidais a obovais, com parede espessa e frequentemente 3-septados, enquanto em E. mexicana os conídios são elipsoidais ou obovais, com uma parede fina e predominantemente 4-septados. O material examinado apresentou conídios maiores que os da descrição (11-16 × 5,8-8,7 $\mu \mathrm{m})$ de Mercado-Sierra et al.(1995)

Hemicorynespora aseptata Hol.-Jech., Česká Mykol. 41(2): 109. 1987.

Figuras 10-11

Colônias em substrato natural efusas. Conidióforos macronemáticos, em feixes ou solitários, retos ou flexuosos, simples, 0-1-septados, lisos, castanhos, cilíndricos a lagenifores, $16-23 \times 3 \mu \mathrm{m}$. Células conidiogênicas monotréticas, terminais, determinadas. Conídios solitários, 0 -septados, secos, lisos, castanhos, navicular-alongados ou elipsoide-alongados, 19-25 × 4-5 $\mu \mathrm{m}$, base cicatrizada, 2-2,5 $\mu \mathrm{m}$ de largura.

Material examinado: BRASIL, PARÁ: Belém, Ilha do Combu, sobre pecíolo de E. oleracea, 11-III-2009, C.C. Castro 50 (MG199651), sobre Corynesporopsis isabelicae Hol.-Jech., 11-III-2009, C.C. Castro 46 (MG199647).

Distribuição geográfica: Cuba (Holubová-Jechová 1987).

Comentários: Hemicorynespora deightonii M. B. Ellis e H. ovata Subram. são as espécies mais semelhantes a $H$. aseptata. Porém, em H. deightonii os conídios são mitriformes e oval-alongados em $H$. ovata. Alguns espécimes foram encontrados como micoparasitas sobre Corynesporopsis isabelicae Hol.-Jech. 
Monodictys paradoxa (Corda) S. Hughes, Can. J. Bot. 36: 786. 1958.

Figura 12

Colônias não observadas. Conidióforos micronemáticos, inflados. Conídios muriformes, secos, lisos, castanho-dourados, às vezes com a célula basal mais clara que as demais, piriformes ou subesféricos, $32-50 \times 25-32 \mu \mathrm{m}$.

Material examinado: BRASIL, PARÁ: Belém, Ilha do Combu, sobre espata de E. oleracea, 03-IV-2009, C.C. Castro 52 (MG199652), raque, 20-VIII-2008, C.C. Castro 15 (MG195851).

Distribuição geográfica: Bielorrússia (Yurchenko 2001), Japão (Matsushima 1975) e Paquistão (Abbas \& Mushtaq 2008).

Comentários: Monodictys paradoxa apresenta semelhanças com $M$. castaneae (Wallr.) S. Hughes, $M$. melanopa (Ach. ex Turner) M. B. Ellis e M. putredinis (Wallr.) S. Hughes. Porém, M. castaneae possui conídios verrucosos; M. melanopa apresenta conídios com células basais claras e apicais castanho-escuras e M.putredinis não possui os conidióforos inflados.

Pithomyces cinnamomeus Hol.-Jech., in HolubováJechová \& Mercado Sierra, Česká Mykol. 38(2): 112. 1984.

Figura 13

Colônias em substrato natural pulvinadas, cor de canela. Conidióforos semimacronemáticos, simples, sub-hialinos a castanho-claros. Conídios acrógenos, solitários, muriformes, levemente constritos nos septos, gutulados, célula basal obcônica, secos, lisos, cor de canela a castanhos, elipsoides ou subglobosos, 20-32 $\times$ 20-25 $\mu \mathrm{m}$.

Material examinado: BRASIL, PARÁ: Belém, Ilha do Combu, sobre folíolo de E. oleracea, 15-XI-2008, C.C. Castro 33 (MG199634).

Distribuição geográfica: Costa Rica e Cuba (Holubová-Jechová \& Mercado-Sierra 1984).

Comentários: Pithomyces obscuriseptatus Matsush. e $P$. sivaramaprasadii N. K. Rao \& Manohar. são as espécies mais semelhantes a $P$. cinnamomeus. Porém, P. obscuriseptatus possui conídos obovoides, verrucosos e com septos obscuros quando maduros (Matsushima 1993); em P. sivaramaprasadii os conídios são esféricos, subesféricos ou elipsoides, finamente verruculosos, pseudoseptados com lúme reduzido e parede ondulada (Rao \& Manoharachary 1988), enquanto em $P$. cinnamomeus os conídios são elipsoides ou subglobosos, lisos e com septação distinta. O material examinado está de acordo com a descrição original (Holubová-Jechová \& Mercado-Sierra 1984).

Pithomyces karoo Marasas \& I. H. Schum., Bothalia 10(4): 511. 1972.

Figura 14

Conidióforos não observados. Conídios solitários, 2-3 septos transversais, 0-1 septo longitudinal, secos, verrucosos, castanho-claros a escuros, clavados, elipsoides ou piriformes, 13-26 × 7-12 $\mu \mathrm{m}$.

Material examinado: BRASIL, PARÁ: Belém, Ilha do Combu, sobre espata de E. oleracea, 15-IX-2008, C.C. Castro 37 (MG199638).

Distribuição geográfica: África do Sul, Austrália (Ellis 1976) e Tailândia (Duong et al. 2008).

Comentários: Pithomyces sacchari (Speg.) M. B. Ellis é a espécie mais próxima de P. karoo. Segundo Matsushima (1981), o pequeno tamanho dos conídios dificulta a distinção entre as espécies, sendo a ornamentação da parede dos conídios a única diferença observada. Em P. karoo os conídios são verrucosos, enquanto em $P$. sacchari são lisos ou levemente rugosos.

Agradecimentos - Ao Museu Paraense Emílio Goeldi-MPEG e ao Laboratório de Micologia (UFPA) pela infraestrutura cedida na realização deste trabalho; ao Conselho Nacional de Desenvolvimento Científico e Tecnológico (CNPq), pela bolsa de concedida ao primeiro autor; ao Dr. Luís Fernando Pascholati Gusmão pela generosa concessão de bibliografia especializada; aos revisores pelas valiosas contribuições.

\section{Referências bibliográficas}

ABBAS, S.Q. \& MUSHTAQ, S. 2008. Addition to the mycoflora of Syzygium cumini from Pakistan. Biannual Journal of Mycology and Phytopathology 6:57-61.

CASTAÑEDA-RUIZ, R.F. \& GUARRO, J. 1998. Two new Hyphomycetes from rainforests of Cuba. Canadian Journal of Botany 76:1584-1588.

CÁUPER, G.C.B., CÁUPER, F.R.M. \& BRITO, L.L.D. 2006. Biodiversidade amazônica. Centro Cultural dos Povos da Amazônia, Manaus, v.1.

CHOI, Y.W., HYDE, K.D. \& HO, W.H. 1999. Single spore isolation of fungi. Fungal Diversity 3:29-38.

CRUZ, A.C.R., HERNÁNDEZ-GUTIÉRREZ, A. \& GUSMÃO, L.F.P. 2008. O gênero Exserticlava (fungo anamorfo - Hyphomycetes) no Brasil. Revista Brasileira de Botânica 31:357-361.

DUONG, L.M., MCKENZIE, E.H.C., LUMYONG, S. \& HYDE, K.D. 2008. Fungal succession on senescent leaves of Castanopsis diversifolia in Doi Suthep-Pui National Park, Thailand. Fungal Diversity 30:23-36. 
ELLIS, M.B. 1976. More dematiaceous Hyphomycetes. Commonwealth Mycological Institute, Kew.

FARR, M.L. 1980. A new species of Cryptophiale from Amazonas. Mycotaxon 11:177-181.

FARR, M.L. 1986. Amazonian foliicolous fungi II. Deuteromycotina. Mycologia 78:269-286.

FERRER, A. \& SHEARER, C.A. 2005. New records and a new species of Canalisporium from aquatic habitats in Panama. Mycotaxon 93:179-188.

GOH, T.K., HO, W.H., HYDE, K.D. \& UMALI, T.E. 1998. New records and species of Canalisporium (Hyphomycetes), with a revision of the genus. Canadian Journal of Botany 76:142-152.

GRANDI, R.A.P. \& GUSMÃO, L.F.P. 2002. O gênero Subulispora Tubaki (Fungos mitospóricos Hyphomycetes) sobre folhas em decomposição no estado de São Paulo, Brasil. Hoehnea 29:31-36.

HAWKSWORTH, D.L. 2002. Why study tropical fungi? In Tropical mycology, v.2. Micromycetes. (R. Watling, J.C. Frankland, M. Ainsworth, S. Isaac \& C.H. Robinson, eds.). CABI Publising, Wallingford, p.1-11.

HEREDIA, G., MENA-PORTALES, J. \& MERCADOSIERRA, A. 1997. Hyphomycetes saprobios tropicales. Nuevos registros de dematiáceos para México. Revista Mexicana de Micología 13:41-51.

HERNÁNDEZ-GUTIÉRREZ, A., MONTEIRO, J.S. \& SOTÃO, H.M.P. 2009. Hifomicetos (fungos anamorfos) associados a palmeiras na Floresta Nacional de Caxiuanã, PA, Brasil. In Caxiuanã: desafios para a conservação de uma floresta nacional na Amazônia (P. Lisboa, ed.). Museu Paraense Emílio Goeldi, Belém, p.397-405.

HO, W.H., HYDE, K.D. \& HODGKISS, I.J. 1999. Digitodesmium recurvum, a new species of cheirosporous hyphomycete from Hong Kong. Mycologia 91:900-904.

HO, W.H., YANNA, HYDE, K.D. \& HODGKISS, I.J. 2002. Seasonality and sequential occurrence of fungi on wood submerged in Tai Po Kau Forest Stream, Hong Kong. In Fungal succession (K.D. Hyde \& E.B.G. Jones, eds.). Fungal Diversity 10:21-43.

HOLUBOVÁ-JECHOVÁ, V. 1982. New or interesting phialidic Hyphomycetes from Cuba. Mycotaxon 15:277292.

HOLUBOVÁ-JECHOVÁ, V. \& MERCADO-SIERRA, A. 1984. Studies on Hyphomycetes from Cuba II. Hyphomycetes from the Isla de la Juventud. Česká Mikologie 38:96-120.

HOLUBOVÁ-JECHOVÁ, V. 1987. Studies on Hyphomycetes from Cuba VI. New and rare species with tretic and phialidic conidiogenous cells. Česká Mykologie 41:107-114.

HOLUBOVÁ-JECHOVÁ, V. \& MERCADO-SIERRA, A. 1989. Hyphomycetes from Loma de la Coca and some localities of La Habana and Matanzas provinces, Cuba. Acta Botánica Cubana 76:1-15.

HUGHES, S. 1978. Endiphragmiella biseptata. Fungi Canadenses 125:1-2.
KIRK, P.M. 1981. New or interesting microfungi II. Dematiaceous Hyphomycetes from Ester Common, Surrey. Transactions of the British Mycological Society 77:279-297.

MATSUSHIMA, T. 1975. Icones microfungorum a Matsushima lectorum. Publicado pelo autor, Kobe.

MATSUSHIMA, T. 1981. Matsushima Mycological Memoirs n. 2. Publicado pelo autor, Kobe.

MATSUSHIMA, T. 1993. Matsushima Mycological Memoirs n. 7. Publicado pelo autor, Kobe.

MERCADO-SIERRA, A. 1984. Hifomicetes demaciáceos de Sierra del Rosario, Cuba. Academia de Ciencias de Cuba, La Habana.

MERCADO-SIERRA, A., HEREDIA-ABARCA, G. \& MENA-PORTALES, J. 1995. New species of dematiaceous Hyphomycetes from Veracruz, Mexico. Mycotaxon 55:491-499.

MONTEIRO, J.S., HERNÁNDEZ-GUTIÉRREZ, A. \& SOTÃO, H.M.P. 2010. Fungos anamorfos (Hyphomycetes) da Floresta Nacional de Caxiuanã, Pará, Brasil. Novos registros para o Neotrópico. Acta Botanica Brasilica 24:868-870.

NEGRÃO, I., SOUZA, J., MACEDO, L., MENDONÇA, M., SANCHES, M., BITAR, P. \& COSTA, P.F. 2009. Diversidade de fungos no estipe do açaizeiro (Euterpe oleracea Mart.). In Diversidade biológica das áreas de proteção ambiental Ilha do Combu e AlgodoalMaiandeua - Pará, Brasil (M.A.G. Jardim, ed.). Museu Paraense Emílio Goeldi, Ministério da Ciência e Tecnologia, Conselho Nacional de Desenvolvimento Científico e Tecnológico, Belém, p.141-145.

PIROZYNSKI, K.A. 1972. Microfungi of Tanzania. I. Miscellaneous fungi on oil palm. II. New Hyphomycetes. Mycological Paper 129:1-65.

RAO, N.K. \& MANOHARACHARY, C. 1988. A new Pithomyces species on leaf litter from A. P., India. Transactions of the British Mycological Society 91: 349-352.

RODRIGUES, K.F. 1994. The foliar fungal endophytes of the Amazonian palm Euterpe oleracea Mart. Mycologia 86:376-385.

SOMRITHIPOL, S. \& JONES, E.B.G. 2003. Berkleasmium typhae sp. nov., a new hyphomycete on narrow-leaved cattail (Typha angustifolia) from Thailand. Fungal Diversity 12:169-172.

SUBRAMANIAN, C.V. 1982. Tropical mycology: future needs and development. Current Science 51:321-325.

SUBRAMANIAN, C.V. \& BHAT, D.J. 1987. Hyphomycetes from South India I. Some new taxa. Kavaka 15:41-47.

YURCHENKO, E.O. 2001. On some wood-inhabiting dematiaceous Hyphomycetes with remarkable conidia in Belarus. Mycena 1:32-54.

ZHAO, G.Z \& ZHANG, T.Y. 2004. Notes on dictyosporic Hyphomycetes from China IV. The genus Berkleasmium. Mycotaxon 89:241-244. 